\title{
Optimizing Gestation and Early Life Physiology through Timing of Energy Turnover: Bioprocessing of Human Life
}

\section{Akbar Nikkhah*}

Chief Highly Distinguished Professor, Department of Animal Sciences, University of Zanjan, Iran

The objective of this perspective article was to describe a novel pragmatic ideology on optimizing pregnancy metabolism and growing child endocrinology and health through timing of energy intake. Energy herein is defined as any substrate that directly or indirectly contributes to fuelling pregnancy progression and growing child development of brain and non-brain cells. Timing of energetic is characterized by adopting optimal circadian occasions (e.g., over an almost 24-h period) for energy-yielding foods and fruits consumption.

Evidence suggests that human develops nocturnal insulin resistance $[1,2]$. The overnight glucose intolerance stems from the evolutionary fact that human is a diurnal creature being active during day and resting overnight. As such, endocrinology and intermediary metabolism have evolved to be activated during day and especially in morning when cells anticipate increased metabolic activity $[3,4]$. Thus, energetic timing will determine how effectively the body can manage the ingested energies in different amounts and forms. Ruminant animal models data indicated that morning versus evening feed delivery once daily significantly alters circadian rhythms of nutrient intake and metabolism as well as nutrient partitioning [5-9]. Such an effect would be of great public health importance in pregnant woman and the resulting child growth and development efficiency.

Pregnancy especially in later stages is known for high development risks of metabolic disorders such as insulin resistance, diabetes, splanchnic and abdominal adiposity and fatty liver $[9,10]$. Disciplined food regimes and appropriate exercise are increasingly being emphasized to prevent such problems and likely to improve foetal and child metabolism and health [10-12]. Timing of energetic through optimizing timing of energy intake can accomplish a great deal of success in managing pregnancy metabolism and health. Accompanied by regular physical activity, optimal timing of energyyielding nutrients intake helps improve the maternal metabolism that is already complicated with the growing foetus physiology and thus the altered nervous and hepatic cell omical properties. Due to the high risk of insulin resistance overnight, large nocturnal food meals and even considerable energy-dense fruits consumption can induce and augment the factors contributing to central obesity and diabetes mellitus development in pregnant women. Such an abnormal maternal metabolism would in many ways impair normal foetal health [13]. This abnormality is subsequently extendable to child development postbirth. Altered foetal genomics, proteomics and metabolomics could, thus, build pathologic foundations for a forthcoming entity as a child, adult and public.

To sum, pregnancy health and metabolism is highly related to the health and wellbeing of the child, adult and public as a whole. Optimizing the timing of energtics through optimal times of energy consumption over the almost 24 -h circadian periods during pregnancy and child growth is a feasible, pragmatic, global and lifetime ideology towards bioprocessing and constructing quality public health.

\section{Acknowledgments}

The Ministry of Science Research and Technology, National Elite Foundation, and University of Zanjan, Iran, are gratefully acknowledged for supporting the author's global programs of optimizing science edification in the third millennium

\section{References}

1. Nikkhah A (2012) Eating time modulations of physiology and health: life lessons from human and ruminant models. Iran J Basic Med Sci 15: 891-899.

2. la Fleur SE, Kalsbeek A, Wortel J, Fekkes ML, Buijs RM (2001) A daily rhythm in glucose tolerance: a role for the suprachiasmatic nucleus. Diabetes 50 : 1237-1243.

3. Nikkhah A (2012) Time of Feeding an Evolutionary Science, Lap Lambert Publishing, GmbH \& Co. KG, Germany.

4. Nikkhah A (2014) Eating timing and diabetes. Int J Diabetol Vas Dis Res 2: 101

5. Nikkhah A (2011) Ruminant chronophysiological management: an emerging bioscience. Open Access Anim Physiol 3: 9-12.

6. Nikkhah A (2013) Chronophysiology of ruminant feeding behavior and metabolism: an evolutionary review. Biol Rhythm Res 44: 197-218.

7. Nikkhah A (2011) Bioscience of ruminant intake evolution: feeding time models. Adv Biosci Biotechnol 2: 271-274.

8. Nikkhah A, Furedi CJ, Kennedy AD, Crow GH, Plaizier JC (2008) Effects of feed delivery time on feed intake, milk production, and blood metabolites of dairy cows. J Dairy Sci 91: 4249-4260.

9. Nikkhah A, C Furedi, A Kennedy, K Wittenberg, JC Plaizier (2010) Morning vs evening feed delivery for lactating dairy cows. Can J Anim Sci 91: 113-122.

10. Sorensen TK, Williams MA, Lee IM, Dashow EE, Thompson ML, et al. (2003) Recreational physical activity during pregnancy and risk of preeclampsia. Hypertension 41: 1273-1280.

11. Dye TD, Knox KL, Artal R, Aubry RH, Wojtowycz MA (1997) Physical activity, obesity, and diabetes in pregnancy. Am J Epidemiol 146: 961-965.

12. Pereira MA, Rifas-Shiman SL, Kleinman KP, Rich-Edwards JW, Peterson $\mathrm{KE}$, et al. (2007) Predictors of change in physical activity during and after pregnancy: Project Viva. Am J Prev Med 32: 312-319.

13. Sebire NJ, Jolly M, Harris JP, Wadsworth J, Joffe M, et al. (2001) Maternal obesity and pregnancy outcome: a study of 287,213 pregnancies in London. Int J Obes Relat Metab Disord 25: 1175-1182.

Corresponding author: Akbar Nikkhah, Chief Highly Distinguished Professor, Department of Animal Sciences, Faculty of Agricultural Sciences, University of Zanjan, Zanjan, Iran, National Elite Foundation, Tehran, Iran, Tel: +98-24-350328-01; Fax: +98-24-350-332-02; E-mail: nikkhah@znu.ac.i

Received February 24, 2015; Accepted February 25, 2015; Published March 13, 2015

Citation: Nikkhah A (2015) Optimizing Gestation and Early Life Physiology through Timing of Energy Turnover: Bioprocessing of Human Life. J Bioprocess Biotech 5: e125 doi:10.4172/2155-9821.1000e125

Copyright: (c) 2015 Nikkhah A. This is an open-access article distributed under the terms of the Creative Commons Attribution License, which permits unrestricted use, distribution, and reproduction in any medium, provided the original author and source are credited. 